\title{
Comparative analysis of combined spinal epidural and spinal plus single shot femoral nerve block as post-operative analgesia in total knee replacement surgery
}

\author{
Shirish Mohan Mahure', Ramprasad Pralhad Chavan², Kalyanji Dedhiya ${ }^{3}$, \\ Dnyanesh Balkrishna Amle ${ }^{4}$
}

\begin{abstract}
${ }^{1}$ Assistant Professor, Department of Anaesthesia, Dr. Panjabrao Alias Bhausaheb Deshmukh Memorial Medical College, Amravati, Maharashtra, India, ${ }^{2}$ Resident, Department of Cardiac Anaesthesiology, Seth G S Medical college and KEM Hospital, Mumbai, ${ }^{3}$ Professor, Department of Anaesthesia, Ashwini Sahkari Rugnalaya and research centre, Solapur, Maharashtra, India, ${ }^{4}$ Assistant Professor, Department of Biochemistry, All India Institute of Medical Sciences, Nagpur, Maharashtra, India
\end{abstract}

\section{A B S T R A C T}

Background: Effective anaesthesia is required to overcome complications of epidural anaesthesia and relieve the patients undergoing lower limb surgeries such as total knee replacement from severe pain. Aims and Objective: The current study was aimed to study combined spinal- epidural anaesthesia (CSEA) and spinal plus single shot femoral nerve block (SSFNB) for post-operative analgesia in total knee replacement surgeries. Materials and Methods: This prospective observational and randomized study included 60 subjects undergoing Total knee replacement which were randomized into two groups and administered combined spinal epidural block and single shot femoral nerve block as per standardised protocol for post-operative pain management. Pain as per visual analogue scale and need of rescue analgesia and other haemodynamic parameters were compared between two groups and at different time interval. Result: Two study groups were found to be matched for age, gender, weigh, height and ASA grading. SSFNB group showed significantly high VAS score at $6 \mathrm{Hr}$, need for rescue analgesia, compared to CSEA group. CSEA group had significantly high number of patients with motor block. significant difference in the variation of pulse rate was observed within both the groups. Significantly higher systolic blood pressure at $6 \mathrm{~h}, 12 \mathrm{~h}, 24 \mathrm{~h}$ and $36 \mathrm{~h}$. , diastolic blood pressure at $6 \mathrm{~h}$, $24 \mathrm{~h}$ and $48 \mathrm{~h}$ and in mean arterial pressure at $6 \mathrm{~h}, 24 \mathrm{~h}$ and $36 \mathrm{~h}$ was observed in SSFNB group compared to CSEA group. Conclusion: We concluded that, patients undergoing total knee replacement show better analgesia and hemodynamic stability with CSEA in comparison to SSFNB, but at the cost of more motor blockade on non-operative limb and delayed recovery.

Keywords: Combined spinal- epidural anaesthesia; Spinal plus single shot femoral nerve block; Total knee replacement; Analgesia

\section{INTRODUCTION}

Major knee surgery as in total knee joint replacement (TKR) is one of the most painful orthopaedic procedures, associated with pain. Post-operative pain is found to be a potent trigger for stress response and is also a causal factor for the adverse effects on various organ systems. Therefore, an effective analgesia may improve the quality of patient outcome as well as may promote attenuation of postoperative physiologic responses and morbidity. ${ }^{1}$ Epidural anaesthesia (EA) is one such widely accepted anaesthesia and offers effective role in pain relief and better 
rehabilitation profiles in patients undergoing such surgeries compared with systemic opioids including intravenous patient controlled analgesia (PCA)., ${ }^{2,3}$ In orthopaedic surgery EA has been prevailing due to reduced blood loss and fewer thromboembolic complications. ${ }^{4}$

However, frequent hypotension, urinary retention, and pruritis have been observed patients receiving EA, whereas systemic opioids have been found to cause elevated sedation. Also, evidences suggest increased risk of serious neurological complications as a result of epidural blockade in patients undergoing TKR. ${ }^{4}$ Regional anaesthesia (RA) is a preferable and an alternative with better postoperative pain management, sufficient and is devoid of opioids, higher patient satisfaction as well as it lowers the risk of pulmonary aspiration, which is the most feared complication of anesthesia. ${ }^{5,6}$

Combined spinal-epidural anaesthesia (CSEA) is a popular approach and reduces and to some extent eliminates the drawbacks of spinal anaesthesia (SA) and EA while preserving their advantages. It is though inappropriate in patients with compromised cardiovascular activity and pulmonary function. Femoral nerve block (FNB) anaesthesia overcomes such complications in the patients undergoing lower limb surgeries as in TKR. ${ }^{6,7}$ Thus we aimed to comparatively study CSEA and spinal plus single shot femoral nerve block (SSFNB) for post-operative analgesia in TKR surgeries.

\section{MATERIALS AND METHODS}

This prospective randomized non blinded study was conducted in the Tertiary care health centre in Solapur. All subjects 40 to 80 years of age posted for unilateral TKR for osteoarthritis of knee and belonged to American Society of Anaesthesiologists (ASA) class 1 to 3 were included in the study. Subjects with history of allergy to local anaesthetics, infection or scarring at the site of FNB, history of surgery or trauma to the operative knee, any previous damage to the nerve/neuropathy, history of lower extremity bypass surgery, psychological disorders or linguistic difficulties that might interfere with pain assessment and patients who refused to give consent were excluded. Ethical approval was obtained from the Institutional ethical committee and written informed consent was obtained from all the subjects. The total of 60 subjects undergoing unilateral TKR surgery were randomized into two groups, CSEA and SSFNB using computer generated block randomization technique. Preoperative clinical assessment, routine investigations and weight of the subjects were recorded and counselling regarding the type of anaesthesia and visual analogue scale (VAS) was provided a day prior to the surgery. Patient was kept Nil by Mouth (NBM) six hours prior to the surgery.

Pulse oximetry, electrocardiography and blood pressure was monitored; antibiotics and $0.03-0.05 \mathrm{mk} / \mathrm{kg}$ midazolam were administered intravenously in all the subjects.

CSEA was given in lateral position with affected side downwards under aseptic conditions with Chlorehexidine and Butadiene. L3- L4 interspace was palpated and infiltrated with $5 \mathrm{~mL}$ of $2 \%$ lignocaine locally using $26-\mathrm{G}$ hypodermic needle. Subarachnoid space was identified using $25-\mathrm{G}$ whitacre spinal needle after confirming free and clear flow of CSF. For SAB $2 \mathrm{ml}$ of $0.5 \%$ of bupivacaine was used. Epidural space was identified using 16-G Tuhoys needle by loss of resistance to air technique. Further, 17-G epidural catheter was introduced $5 \mathrm{~cm}$ into the epidural space. Catheter was secured using sterile transparent dressing. Preoperative sensory level of T10 was achieved. Epidural test dose given using lignocaine $2 \%$ with adrenaline $5 \mathrm{mcg} / \mathrm{ml}$ and epidural infusion of $0.25 \%$ bupivacaine was started at $2 \mathrm{ml} /$ hour and later increased to $6-8 \mathrm{ml} /$ hour after 2 hours of surgery, on necessity basis.

In SSFNB group epidural was not activated, after completion of surgery single shot femoral nerve block under USG guidance was given using $0.25 \%$ bupivacaine $30 \mathrm{ml}$.

Post-operative hemodynamic monitoring was continued and data on pain scores using VAS was noted and any associated adverse effects were noted for the next 48 hours. Patients were asked to point out the intensity of pain on the VAS pain scale. In case the subject complained of pain rescue analgesia in the form of Tramadol $50 \mathrm{mg}$ was given intravenously. Total number of doses of rescue analgesics administered to the subjects during first 24 hours was noted. After 24 hours oral analgesic T. paracetamol $650 \mathrm{mg}$ QID was added as a part of multimodal analgesia in both the groups.

All the subjects were monitored on regular basis by an acute pain services (APS). Data was collected and expressed as frequency (percent) and mean \pm SD. $\mathrm{P}$ value $<0.05$ was considered as statistically significant. SPSSC for windows ${ }^{\mathrm{TM}}$ Vs 17, IBM ${ }^{\mathrm{TM}}$ Corp NY and Microsoft excel ${ }^{\mathrm{TM}} 2007$, Microsoft ${ }^{\circledR}$ Inc USA was used to perform the statistical analysis.

\section{RESULTS}

Table 1 shows general characteristics in study subjects. Total 30 subjects were recruited in each group. The groups 
were matched for age $(\mathrm{p}>0.05)$, weight $(\mathrm{p}>0.05)$, height $(p=0.39)$, gender $(p>0.05)$ and ASA grade $(p>0.05)$.

Table 2 shows comparison of visual analogue score at activity in the studied groups. In both group observed rise in VAS score as compared with VAS of 0 hour was statistically significant when analysed by Wilcoxon signed ranked test with $(\mathrm{p}<0.05)$. Both groups showed significantly high VAS scores after 6 hours onward as compared to baseline 0 hour. Zero h, 12h, 24h, 36h and $48 \mathrm{~h}$ no significant difference observed between the groups. However, at 6h VAS was found to be significantly higher in subjects who underwent SSFNB anaesthesia.

Figure 1 indicates the need for rescue analgesia and Bromage score of motor blockage on postoperative day one in the study groups. The need for rescue analgesia was significantly higher in SSFNB group $(p<0.05)$. In CSEA group $60 \%$ patients had no motor blockade i.e. Bromage score of 1 , while $40 \%$ patients had Bromage score of 2 (partial block) in both lower limbs, while in SSFNB group patients had no motor blockade, all patients had Bromage score of 1 , on postoperative day 1 after surgery. CSEA group had significantly high number of patients with motor block $(\mathrm{p}<0.05)$ (Figure 2).

Table 3 shows comparison of mean pulse rate between the studied groups. There was no significant difference between two study groups regarding pulse rate $(p>0.05)$.

\begin{tabular}{|c|c|c|c|c|}
\hline & $\begin{array}{l}\text { Group } \\
\text { (ICSEA) }\end{array}$ & $\begin{array}{l}\text { Group II } \\
\text { (SSFNB) }\end{array}$ & $T$ value & $P$ value \\
\hline Age & $63.7 \pm 8.06$ & $62.9 \pm 5.36$ & 0.87 & $p>0.05$ \\
\hline Weight & $74.2 \pm 8.38$ & $73.0 \pm 8.48$ & 1.33 & $p>0.05$ \\
\hline Height & $157.6 \pm 8.38$ & $158.5 \pm 8.56$ & 0.85 & 0.39 \\
\hline \multicolumn{5}{|l|}{ Gender } \\
\hline Male & $18(60 \%)$ & $12(40 \%)$ & 0.606 & $p>0.05$ \\
\hline Female & $12(40 \%)$ & $15(50 \%)$ & & \\
\hline \multicolumn{5}{|l|}{ Grade } \\
\hline ASA I & $4(13.33 \%)$ & $3(10 \%)$ & & $p>0.05$ \\
\hline ASA II & $26(86.66 \%)$ & $26(86.66 \%)$ & & \\
\hline ASA III & 0 & $1(3.33 \%)$ & & \\
\hline
\end{tabular}

Table 2: Comparison of visual analogue score at
activity in the studied groups
\begin{tabular}{lcccc} 
Time & $\begin{array}{c}\text { Group I } \\
\text { (CSEA) } \\
\text { (30) }\end{array}$ & $\begin{array}{c}\text { Group II } \\
\text { (SSFNB) }\end{array}$ & $\begin{array}{c}\text { Mann- Whitney } \\
\text { U test }\end{array}$ & P Value \\
\hline $0 \mathrm{~h}$ & $0.3 \pm 0.65$ & $0.3 \pm 0.65$ & 450 & $>0.05$ \\
$6 \mathrm{~h}$ & $1.77 \pm 0.50^{*}$ & $3.8 \pm 0.40^{* *}$ & 3 & $<0.05$ \\
$12 \mathrm{~h}$ & $2.63 \pm 0.49^{*}$ & $2.73 \pm 0.74^{* *}$ & 436 & $>0.05$ \\
$24 \mathrm{~h}$ & $2.7 \pm 0.46^{*}$ & $2.8 \pm 0.6^{* *}$ & 365 & $>0.05$ \\
$36 \mathrm{~h}$ & $3.03 \pm 0.32^{*}$ & $2.97 \pm 0.41^{* *}$ & 422 & $>0.05$ \\
$48 \mathrm{~h}$ & $2.97 \pm 0.49^{*}$ & $3.1 \pm 0.5^{* *}$ & 410 & $>0.05$ \\
\hline
\end{tabular}

* $p$ value within group I as compared to VAS at o $h$ using Wilcoxon sign rank test **p value within group II as compared to VAS at o h using Wilcoxon sign rank test
However, significant difference in the variation of pulse rate was observed within the groups.

Table 4 compares the blood pressure (BP) between the studied groups. The systolic blood pressure (SBP) at $0 \mathrm{~h}$ and $48 \mathrm{~h}$ the SBP were matched for both the groups. While significant difference in mean SBP was observed between the two groups at $6 \mathrm{~h}, 12 \mathrm{~h}, 24$ and $36 \mathrm{~h}$. The subjects in group II were found to have higher mean SBP. Statistically significant difference was observed between the two groups regarding Diastolic BP (DBP) at $0 \mathrm{~h}, 6 \mathrm{~h}, 24 \mathrm{~h}$ and $48 \mathrm{~h}$. While, the groups were found to be matched for DBP at $12 \mathrm{~h}$ and $36 \mathrm{~h}$. Mean arterial blood pressures (MAP) at $0 \mathrm{~h}$, $6 \mathrm{~h}, 24 \mathrm{~h}$ and $36 \mathrm{~h}$ was found to be significantly different while, MAP of subjects at $12 \mathrm{~h}$ and 48 were found to be matched for the groups.

\section{DISCUSSION}

TKR is a common surgery which improves mobility and quality of life. The pain after TKR is severe and persists for 48-72 hours after the surgery. ${ }^{4}$ Effective analgesia allows for earlier ambulation and initiation of physiotherapy, which hastens functional recuperation, reduces the length of stay in the hospital, and lowers the risk of postoperative complications, such as thromboembolic disease or nosocomial infections. ${ }^{8}$

PCA (opioids) and EA and FNB are commonly used analgesic options for TKR. PCA morphine or other opioids

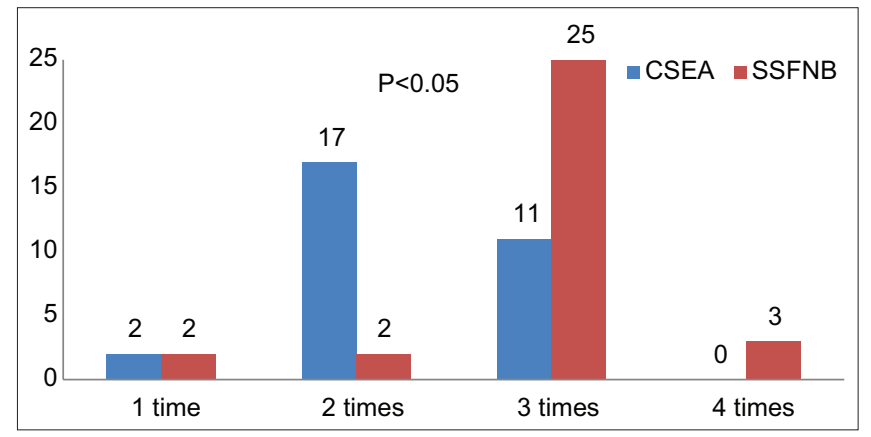

Figure 1: Comparison of rescue analgesia needed in two groups

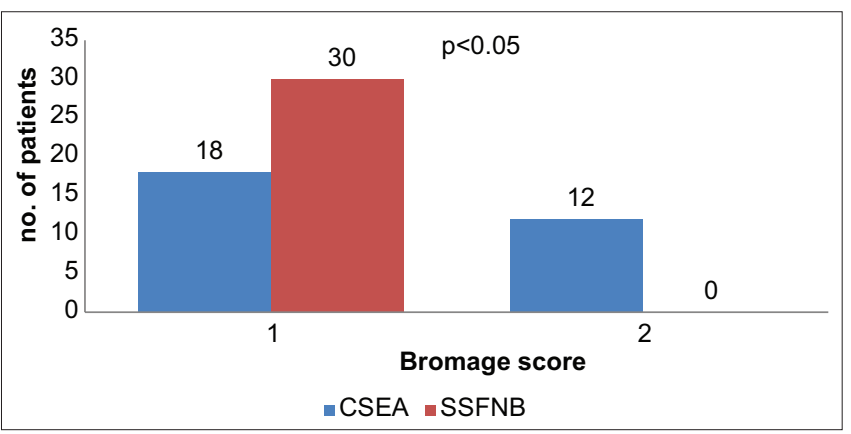

Figure 2: Comparison of Bromage score of Motor blockade on POD 1 


\begin{tabular}{|c|c|c|c|c|}
\hline Time & $\begin{array}{c}\text { Group I } \\
\text { (CSEA) (30) }\end{array}$ & $\begin{array}{c}\text { Group II } \\
\text { (SSFNB) (30) }\end{array}$ & t- Test & PValue \\
\hline $\mathrm{Oh}$ & $78.87 \pm 12$ & $78.1 \pm 11.56$ & 0.85 & $>0.05$ \\
\hline $6 \mathrm{~h}$ & $89.26 \pm 13^{*}$ & $88.1 \pm 12.5^{\star *}$ & 0.92 & $>0.05$ \\
\hline $12 \mathrm{~h}$ & $89.9 \pm 14.9^{*}$ & $86.26 \pm 12.12^{\star *}$ & 1.46 & $>0.05$ \\
\hline $24 \mathrm{~h}$ & $90.43 \pm 13.4^{*}$ & $86.4 \pm 11.3^{* *}$ & 1.66 & $>0.05$ \\
\hline $36 \mathrm{~h}$ & $87.25 \pm 9.1^{*}$ & $83.43 \pm 8.9^{* *}$ & 2.01 & 0.05 \\
\hline $48 \mathrm{~h}$ & $85.1 \pm 7.84^{*}$ & $82.7 \pm 8.8^{\star *}$ & 1.53 & $>0.05$ \\
\hline
\end{tabular}

\begin{tabular}{|c|c|c|c|c|}
\hline Time & $\begin{array}{c}\text { Group } \\
\text { I (CSEA) (30) }\end{array}$ & $\begin{array}{c}\text { Group } \\
\text { II (SSFNB) (30) }\end{array}$ & t- Test & PValue \\
\hline \multicolumn{5}{|c|}{ Systolic blood pressure } \\
\hline $\mathrm{Oh}$ & $117.73 \pm 20.9$ & $124.03 \pm 16$ & 1.69 & $>0.05$ \\
\hline $6 \mathrm{~h}$ & $125.0 \pm 24.4^{*}$ & $140.3 \pm 17.9^{* *}$ & 3.14 & $<0.05$ \\
\hline $12 \mathrm{~h}$ & $126.13 \pm 23.5^{\star}$ & $135.9 \pm 18^{* *}$ & 2.17 & $<0.05$ \\
\hline $24 \mathrm{~h}$ & $119.8 \pm 20.94^{*}$ & $133.1 \pm 21.7^{* *}$ & 2.77 & $<0.05$ \\
\hline $36 \mathrm{~h}$ & $125.57 \pm 20.4^{*}$ & $134.2 \pm 14.1^{* *}$ & 2.38 & $<0.05$ \\
\hline $48 \mathrm{~h}$ & $125 \pm 57^{*}$ & $131.93 \pm 15.16^{\star \star}$ & 1.85 & $>0.05$ \\
\hline \multicolumn{5}{|c|}{ Diastolic blood pressure } \\
\hline $\mathrm{Oh}$ & $65.8 \pm 12.15$ & $72.4 \pm 12.15$ & 2.68 & $<0.05$ \\
\hline $6 \mathrm{~h}$ & $67.83 \pm 12.8^{*}$ & $76.26 \pm 8.3^{\$}$ & 3.40 & $<0.05$ \\
\hline $12 \mathrm{~h}$ & $72.36 \pm 14.7^{\star \$}$ & $75.5 \pm 11.66^{\$}$ & 1.36 & $>0.05$ \\
\hline $24 \mathrm{~h}$ & $69.13 \pm 16.22^{*}$ & $77.5 \pm 9.78^{\$}$ & 2.76 & $<0.05$ \\
\hline $36 \mathrm{~h}$ & $70.9 \pm 14.4^{*}$ & $75.83 \pm 12.2^{\$}$ & 1.81 & $>0.05$ \\
\hline $48 \mathrm{~h}$ & $73.1 \pm 12.3^{*}$ & $77.0 \pm 9.33^{\$}$ & 2.07 & $<0.05$ \\
\hline \multicolumn{5}{|c|}{ Mean arterial pressure } \\
\hline $\mathrm{Oh}$ & $83.11 \pm 14.5$ & $89.3 \pm 11.5$ & 2.19 & $<0.05$ \\
\hline $6 \mathrm{~h}$ & $86.88 \pm 15.59^{\star}$ & $99.43 \pm 9.85^{\star \star}$ & 4.16 & $<0.05$ \\
\hline $12 \mathrm{~h}$ & $90.28 \pm 16.36^{*}$ & $95.36 \pm 12.6^{* *}$ & 1.74 & $>0.05$ \\
\hline $24 \mathrm{~h}$ & $86.0217 .46^{*}$ & $95.7612 .04^{* *}$ & 2.87 & $<0.05$ \\
\hline $36 \mathrm{~h}$ & $88.93 \pm 14.7^{\star}$ & $95.03 \pm 10.88^{* *}$ & 2.19 & $<0.05$ \\
\hline $48 \mathrm{~h}$ & $90.5 \pm 13.5^{*}$ & $95.6 \pm 11^{* *}$ & 1.94 & $>0.05$ \\
\hline
\end{tabular}

are frequently used as the primary analgesic for TKR. EA is associated with the risk of neuraxial haematomas, unwanted hypotension and bilateral lower limb motor block. Systemic opioids are a popular postoperative analgesic regimen, but these are associated with side effects of nausea, vomiting, pruritus and sedation.

Most of the studies available in literature have compared analgesia outcomes after continuous EA and continuous FNB. There are very few studies which used SSFNB as a post analgesia plan. The pain after TKR surgeries is moderate to severe. SSFNB may not be sufficient for analgesia, so it can be part of multimodal analgesia regime either it can be use concomitantly with Continuous epidural infusion (CEI) or IV PCA. With advances in technology and introduction of ultrasound in regional anaesthesia one can be assure of action of femoral block. In our study both the group epidural was placed in situ, because mean surgical time for TKR in our institute was $3-3.5$ hours both groups started epidural after two hours of surgery to maintain adequate sensory and motor level. In SSFNB group epidural infusion was concluded immediately at the end of surgery and ultrasound guided SSFNB was given and patient shifted to PACU for monitoring.

We found that demographic parameters like age, sex, weight, height and ASA grade were comparable in both the study groups. In a study done by Shanthanna $\mathrm{H}$, Huilgol M, and et al in 2012 comparative study of ultrasound-guided continuous FNB with continuous EA for pain relief following TKR found no difference in demographic profile of both the groups. ${ }^{9}$ In study done by LEE AR et al in 2011, effect of combined single-injection FNB and patient-controlled EA in patients undergoing TKR they found no difference in demographic data. ${ }^{10}$ Our study can be compared with study done by Lee $e t$ al as there was no significant differences in demographic data. ${ }^{2}$

We found that the peak of mean VAS score in CSEA group was around 12 hours period $2.6 \pm 0.49$, hence we came to know that CSEA group patients were more comfortable with lower pain scores in initial post op hours. VAS score rises slowly to peak around 24 hours after that it remains at that level. Whereas in SSFNB group mean VAS score was significantly high at 6 hours $3.8 \pm 0.04$ (peak) after that at 12, 24, 36 and 48 hours VAS score shows decreasing trend which was apparently higher than CSEA group. It could be managed with rescue analgesia. In both the groups mean VAS score remained in low bearable range $3-4$.

In the study by Sundarathiti $\mathrm{N}$ et al. ${ }^{11} 31$ patients received a CSEA; 30 patients received SA and CFNB. They found that there were no significant differences in the VAS scores for the first hour and at postoperative12-72 $\mathrm{hr}$ between the two groups. At postoperative6-12 hr, the VAS scores were significantly greater in the CFNB compared with the CEI. Shanthana et al in 2012 did a comparative study of ultrasound-guided continuous FNB with continuous EA for pain relief following total knee replacement and found that mean VAS score was significantly high in CFNB group than CEI at 6 hours and after that mean VAS scores did not show significant difference between the groups and also requirement of rescue analgesic was more in SSFNB group. ${ }^{9}$ Our study shows almost consistent results with this study hence our study can be compared with study of Sundarathiti $\mathrm{N}$ et al. ${ }^{11}$ and shanthana and et al in 2012. ${ }^{9}$

Our study is further can be supported by meta-analysis of randomized controlled trials by Fowler and $e t$ al ${ }^{4}$, which showed that peripheral nerve blocks provides equal 
analgesia except for first 6 hours .also common side effects were more common in CSEA group.

Barrington $\mathrm{MJ}$ et al ${ }^{2}$ found patients in CFNB group received more Oxycodone (13/12 mg) and Rofecoxib (70/ $60 \mathrm{mg}$ ) than did CEA group. There were no differences between groups in the number of patients requiring IV morphine. In their study CFNB group had a infusion of plain bupivacaine $0.2 \%$ at $0.1 \mathrm{ml} / \mathrm{kg} / \mathrm{hr}$ with a PCA in contrast to epidural group where infusion of ropivacaine $0.2 \%$ plus Fentanyl $14 \mathrm{mcg} / \mathrm{ml}$ commenced at $6-10 \mathrm{ml} / \mathrm{hr}$ this may the reason to for increased analgesic consumption in CFNB group. In our study Fentanyl was not added to both groups, rescue analgesic requirement was more in SSFNB group because of pain in posteromedial aspect of knee which was not blocked by SSFNB.

Looking at the trends over a period of time the hemodynamic parameters viz. Pulse rate, SBP, DBP, MAP had shown peaks and troughs coinciding with mean VAS score in both groups. As compared to CSEA group, in SSFNB group all hemodynamic parameter are increased after 6 hours and remained at that level then slowly decreased to be equal with CSEA at around 48 hours, this was because sympathetic stimulation due to pain. Whereas in CSEA group patients had sympathetic blockade due to CEI which lead to relatively stable hemodynamic parameters and lower VAS scores. All hemodynamic parameters were compared with ' 0 ' hours (that is at the end of surgery) as a baseline when FNB was given. If this could have been compared with preoperative values the difference (rise) in hemodynamic parameters SSFNB group may not have been significant as many of these patients were hypertensive and diabetic. In a study by Dauri $\mathrm{M}$ et al. ${ }^{13}$ author did not find significant differences in MAP, HR and RR.

\section{Limitations of the study}

Though the study followed a robust research model, our study was limited by a small sample size. Replication of study in larger population and at multiple centres will be helpful in generalising the results of study.

\section{CONCLUSION}

We conclude that patients of CSEA group had better analgesia and hemodynamic stability, but at the cost of more motor blockade on non-operative limb and delayed recovery. This study shows that ultrasound guided single shot femoral nerve block with bupivacaine $0.25 \% 30 \mathrm{ml}$, can provide adequate post-operative analgesia in addition to oral analgesics postoperatively in TKR patients. A PNB technique which includes femoral block represents the best balance between analgesia and side-effects as a choice of postoperative analgesic technique for major knee surgery such as TKR, especially as the risk of injury to the neuraxis is negligible. Data are urgently required comparing efficacy and morbidity of single-shot blocks compared with perineural catheter techniques, preferably with a large randomized controlled trial so that a meaningful comparison of less common complications can be undertaken. More work is also needed to prove that newer techniques offer important advantages such as faster return to normal daily activities, decreased morbidity, and improved patient satisfaction. As with all aesthetic and the risk of system error, it is important to consider risk-benefit on a patient-by-patient basis and tailor the analgesic technique accordingly.

\section{ACKNOWLEDGEMENT}

The authors take this opportunity to thank Department of orthopaedics for their whole hearted support for this study.

\section{REFERENCES}

1. Liu S, Carpenter RL and Neal JM. Epidural anesthesia and analgesia: their role in postoperative outcome. The Journal of the American Society of Anesthesiologists. 1995; 82(6):14741506.

https://doi.org/10.1097/00000542-199506000-00019

2. Lee AR, Choi DH, Ko JS, Choi SJ, Hahm TS, Kim GH, et al. Effect of combined single-injection femoral nerve block and patient-controlled epidural analgesia in patients undergoing total knee replacement. Yonsei Medical Journal. 2011; 52(1):145. https://doi.org/10.3349/ymj.2011.52.1.145

3. Lang SA. Postoperative analgesia following total knee arthroplasty: a study comparing spinal anesthesia and combined sciatic femoral 3-in-1 block. Regional Anesthesia and Pain Medicine. 1999; 24(1):97.

https://doi.org/10.1016/S1098-7339(99)90176-1

4. Fowler SJ, Symons J, Sabato S and Myles PS. Epidural analgesia compared with peripheral nerve blockade after major knee surgery: a systematic review and meta-analysis of randomized trials. British Journal of Anaesthesia. 2008; 100(2):154-164.

https://doi.org/10.1093/bja/aem373

5. Álvarez NE, Ledesma RJ, Hamaji A, Hamaji MW and Vieira JE. Continuous femoral nerve blockade and single-shot sciatic nerve block promotes better analgesia and lower bleeding for total knee arthroplasty compared to intrathecal morphine: a randomized trial. BMC Anesthesiology. 2017; 17(1):1-6. https://doi.org/10.1186/s12871-017-0355-x

6. El-Badawy HA, Yousef AA, El-Mawy GM and El-Kalawy ES. Comparative study between combined spinal-epidural anesthesia versus femoral/sciatic nerve block under ultrasound and nerve stimulator guidance for both-bone leg fractures. Tanta Medical Journal. 2018; 46(1):54.

https://doi.org/10.4103/tmj.tmj_46_17

7. Green L and Machin SJ. Managing anticoagulated patients during neuraxial anaesthesia. British Journal of Haematology. 2010; 149(2):195-208. 
https://doi.org/10.1111/j.1365-2141.2010.08094.x

8. Richman JM and Wu CL. Epidural analgesia for post-operative pain. Anesthesiol Clin North Am. 2005; 23:125-140.

https://doi.org/10.1016/j.atc.2004.11.004

9. Shanthanna H, Huilgol M, Manivackam VK and Maniar A. Comparative study of ultrasound-guided continuous femoral nerve blockade with continuous epidural analgesia for pain relief following total knee replacement. Indian Journal of Anaesthesia. 2012;56(3):270

https://doi.org/10.4103/0019-5049.98776

10. Kollmann-Camaiora A, Brogly N, Alsina E and Gilsanz F. Use of the cumulative sum method (CUSUM) to assess the learning curves of ultrasound-guided continuous femoral nerve block. Revista Española de Anestesiología y Reanimación (English Edition). 2017;64(8):453-459.

https://doi.org/10.1016/j.redare.2017.06.002
11. Sundarathiti $P$, Ruananukul N, Channum $T$, Kitkunasathean $C$, Mantay A, Thammasakulsiri J, et al. A comparison of continuous femoral nerve block and continuous epidural analgesia in post-operative analgesia and rehabilitation after total knee arthroplasty. J Med Assoc Thia. 2009; 92 (3): 328-334.

12. Barrington MJ, Olive D, Low K, David S, Jennifer B and Peter C. Continuous femoral blockade or epidural analgesia after total knee replacement: a prospective randomized controlled trail. Anesth Analg. 2005; 101:1824-1829. https://doi.org/10.1213/01.ANE.0000184113.57416.DD

13. Dauri M, Polzoni M, Fabbi E, Sidiropoulou T, Servetti $S$, Coniglione F, Mariani P and Sabato AF. Comparison of epidural, continuous femoral and intraarticular analgesia after anterior cruciate ligament reconstruction. Acta Anaesthesiol Scand. 2003; 47: 20-25

https://doi.org/10.1034/j.1399-6576.2003.470104.x

\footnotetext{
Author's contribution:

SM - Prepared first draft of manuscript; RC - Data collection; KD - Concept, coordination of study review of manuscript preparation;
}

DA - Statistically analysed and interpreted, preparation of manuscript and revision of the manuscript.

\section{Work Attributed to:}

Ashwini Sahkari Rugnalaya and research centre, Solapur, MS, India.

Orcid ID:

Dr. Shirish Mohan Mahure - (1) https://orcid.org/0000-0001-5969-5415

Dr. Ramprasad Pralhad Chavan - io https://orcid.org/0000-0002-6055-6639

Dr. Kalyanji Dedhiya - (D) https://orcid.org/0000-0001-7864-6061

Dr. Dnyanesh Balkrishna Amle - (D) https://orcid.org/0000-0002-5162-840X

Source of Funding: None, Conflicts of Interest: None. 